\title{
White House bill would ban human cloning
}

[WASHINGTON] Acting on the advice of his bioethics advisory commission, President Bill Clinton on Monday sent to Capitol Hill legislation banning anyone in the public or private sector from using cloning to create children. The legislation would expire in five years, forcing a review at that time.

Clinton said he was acting on a "national consensus" that "attempting to clone a human being is unacceptably dangerous to the child and morally unacceptable to our society". Clinton said that the bill will not ban animal research or the cloning of DNA in cells, and argued that the cloning of a sheep reported by Scottish scientists in February promises "revolutionary new medical technologies".

But his bill, he said, "will ensure that we do not fall prey to the temptation to replicate ourselves at the expense of those beliefs and the lives of innocent children we would produce". Clinton also said that his March ban on federal funding for cloning human beings will remain in place "until the day I sign the legislation into law". And he reiterated his call to the private sector to refrain from attempting to clone humans.

Under the Clinton bill, the National Bioethics Advisory Commission (NBAC), would be required to continue studying cloning, reporting to Clinton again six months before the law expired.

The NBAC last week decided it was premature to reach a position on whether the cloning of humans to produce offspring is ethically acceptable or not, calling only for a provisional legislative ban on the grounds of safety.

In a report submitted to Clinton on
Monday, the NBAC said that the need for a permanent law remained "an open question" for Americans to decide, given the "more speculative" nature of ethical questions concerning the possible psychological risk to clones, and cloning's impact on social mores. These, it wrote, "may or may not be enough to justify prohibitions in the future".

Although the commission described human cloning for reproductive purposes as "morally unacceptable" at present, it based its recommendation on safety considerations. It argued that "the use of this technique to create a child would be a premature experiment that would expose the fetus and the developing child to unacceptable risks".

Indeed, Dolly, the first animal to be produced using nuclear transfer cloning techniques, was the only cloned lamb to result from 277 fusions involving adult cells, and no information is yet available on her longevity, fecundity or susceptibility to diseases such as cancer.

In its report, the commission said that safety concerns alone were "sufficient to justify a prohibition on cloning human beings at this time". At the same time, it acknowledged that the use of such techniques might be "characterized as the exercise of a fundamental [constitutional] right to attempt to procreate". In a further indication of the uncertainties in the debate, the commission recommended that any legislation should automatically expire after three to five years, in order to force a review of its appropriateness as science evolves.

In a move that drew praise from some scientists, NABC did not call for restrictions on cloning research that stops short of implantation, leaving open the possibility that researchers in the private sector could use the technique to create embryos for in vitro studies. This is "a good thing", said Roger Pedersen, a mammalian embryologist at the University of California, San Francisco. "This kind of research could have tremendous value to people."

While not the intent of the 18-member commission, this exception might in practice open the way to resolving some safety concerns of human cloning, and bring a step closer the feasibility of cloning human offspring. Although federal funding for human embryo research is currently prohibited by law, such research is allowed in the private sector.

In recommending the broader law against cloning for implantation, the commission argued that "the history of infertility treatment - especially that of in vitro fertilization - demonstrates that where there is a sizeable and well financed demand for a novel service, there will be professionals willing to try to provide it".

NBAC cautioned that legislation should be carefully written "so as not to interfere with other important areas of scientific research" such as cloning of cell lines and DNA sequences.

But some scientists regret the call for legislation. "This would add strength to the effort to criminalize other aspects of [cloning] research, including perhaps in vitro studies," says Pedersen. "It provides an avenue for politically based regulation of research."

MeredithWadman

\section{US opens reagent repository to boost malaria vaccine research}

[WASHINGTON] A reagent repository intended to give a 'jump start' to malaria vaccine research by supporting established investigators and attracting new scientists into the field is being opened by the US National Institute of Allergy and Infectious Diseases (NIAID).

"Everything from insects through malaria antigens [to] immune sera [will be] made freely available to any investigators who have a good faith effort in wanting to do malaria research," Anthony Fauci, the director of NIAID, said last week.

Fauci announced the plan for the repository - part of a ten-year NIAID malaria vaccine development strategy - at a meeting of the Advisory Committee to Harold Varmus, the director of the National Institutes of Health (NIH).

The proposal grew in part from an international meeting on malaria research held in Dakar, Senegal, in January, in which
Fauci and Varmus participated (see Nature $386,539 ; 1997)$. Both will travel to a followup meeting in the Hague early next month at which participating organizations hope to agree on a collaborative international system to review and fund malaria work.

According to Varmus, the meeting at the Hague will provide a "pivotal moment" in which participating groups will decide whether to adopt "a radical approach of putting money in a common pot", an idea he raised in Dakar.

Alternatively, the groups could in principle decide to stick with the status quo. Or they may decide to develop a common application and review process, but allow individual organizations to maintain control of their own money by choosing which of the projects approved by the common review body they will fund.

While NIH money will be at stake, Varmus said, "also at stake will be the fortunes of the people in the world who are affected by this disease". Fauci said that the amount of money made available under any of these schemes will depend on the quality of the research ideas solicited since January. At the high end, he said, the figure might reach $\$ 50$ or $\$ 100$ million.

At last week's NIH meeting, Fauci said he plans to use between $\$ 200,000$ and $\$ 400,000$ "immediately" to start a repository housed initially within existing NIAID contract operations near NIH's campus in Bethesda, Maryland, but soon supported by its own \$1-\$1.5 million yearly contract. The money would augment the NIAID's current malaria budget, estimated at \$21.8 million in 1997.

The goal, according to Fauci, is "to allow malaria investigators to compete effectively against the broad pool of [grant applicants]". In the malaria vaccine research field, "you can't do that unless you have some of these reagents". 